Vol. 2 | No. 3 | 2021 | Hal. 188-193

\title{
STRATEGI PEMASARAN MELALUI MEDIA ONLINE PADA PRODUK USAHA RUMAHAN BANANA CHIPS
}

\author{
Sunawan*, Eeb Saifullah Fatah, Mirna Febi Alfisyah, Rabiatul Arabiah, Sadiyatul \\ Islami, Salsabila Nurul Izha, Novia Putri Dewi, Siti Nurhalimah, Navis Febiansyah, \\ Muhammad Taufik, Rudi Efendi, Husna Mahendra Putra
}

Fakultas Pertanian, Universitas Islam Malang

*korespondensi email: sunawan@unisma.ac.id

\begin{abstract}
ABSTRAK
Desa Bandungrejo sebagai sentra daerah penghasil pisang dan memiliki potensi nilai ekonomi bagi masyarakat. Disetiap pekarangan rumah milik warga memiliki tanaman pohon pisang,namun komoditi pisang disini kurang mendapat perhatian sehingga komoditi pisang bukan menjadi sumber penghasilan utama bagi setiap keluarga karena harga jual yang masih rendah. Sehingga perlakuan untuk buah pisang hanya sebatas dikonsumsi untuk keluarga seperti di goreng dan dikukus. Belum ada yang mengambil kesempatan untuk berinovasi mengolah buah pisang menjadi nilai jual. Dalam upaya untuk menumbuhkan motivasi dan kemampuan para ibu rumah tangga itu, diperlukan penyuluhan dan pelatihan yang dapat menggerakkan para ibu untuk menemukan, mengembangkan dan meningkatkan potensi dirinya. Dengan adanya kesadaran dan motivasi tersebut, diharapkan para ibu dapat bertindak lebih jauh dan turut andil dalam menyelesaikan persoalan perekonomian keluarga. Dalam hal ini, potensi diri memiliki pengertian yang umumnya relatif dapat dipahami dengan mudah.
\end{abstract}

Kata Kunci: pemasaran; media online; banana chip

\section{PENDAHULUAN}

Pemberdayaan berasal dari kata dasar daya yang mengandung arti "kekuatan", dan merupakan terjemahan dari istilah dalam bahasa Inggris "empowerment", sehingga dapat dijabarkan bahwa pemberdayaan mengandung arti memberikan daya atau kekuatan kepada kelompok yang lemah yang belum mempunyai daya/kekuatan untuk hidup mandiri, terutama dalam memenuhi kebutuhan pokok/kebutuhan dasar hidupnya seharihari seperti makan, pakaian/sandang, rumah/papan, pendidikan, kesehatan. Pemerintah memiliki tanggungjawab untuk memberikan kekuatan atau power kepada orang yang kurang mampu atau miskin atau powerless. Hal tersebut harus didukung penuh oleh berbagai pihak, terutama masyarakat itu sendiri yang menjadi kelompok sasaran yaitu dengan ikut berpartisipasi dalam pelaksanaan setiap program/kegiatan pemberdayaan (Hamid, 2018; Hatneny et al., 2019; Sugiri, 2012).

Desa Bandungrejo adalah daerah sentra penghasil pisang dan memiliki potensi nilai ekonomi bagi masyarakat. Keadaan tanah di Desa Bandungrejo termasuk subur yang sebagian besar didominasi oleh lahan pertanian, pekarangan dan pemukiman. Disetiap pekarangan rumah warga memiliki tanaman pohon pisang, namun komoditi pisang disini kurang mendapat perhatian dari masyarakat di desa bandungrejo sehingga komoditi pisang bukan menjadi sumber penghasilan utama bagi setiap keluarga karena harga jual yang masih rendah dan belum ada yang mengambil kesempatan untuk berinovasi. Sehingga perlakuan 
masyarakat untuk buah pisang hanya sebatas dikonsumsi untuk keluarga seperti di goreng dan dikukus. Belum ada yang mengambil kesempatan untuk mengolah buah pisang menjadi nilai jual yang lebih tinggi.

Berdasarkan hasil observasi langsung oleh tim KSM-Tematik Kelompok 93 yang telah di lakukan di desa Bandungrejo dusun Sumberagung dapat diambil kesimpulan bahwa potensi nilai ekonomi dalam pengolahan pisang sebagai komoditi lokal belum bisa dikatakan maksimal, karena perlakuan masyarakat di desa Bandungrejo dalam pengolahan buah pisang hanya sebatas untuk dikonsumsi sendiri dan belum adanya suatu inovasi yang mengambil kesempatan pengolahan buah pisang tersebut menjadi nilai jual yang lebih tinggi, hampir semua ibu rumah tangga yang tinggal di desa Bandungrejo sangat aktif dalam kegiatan sosial masyarakat. Namun sangat disayangkan dalam urusan ekonomi keluarga di desa Bandungrejo belum banyak dari mereka yang terlibat secara aktif membantu meningkatkan perekonomian keluarga.

Terkait dengan fenomena sosial ekonomi di desa Bandungrejo, Ibu-ibu yang tergabung dalam PKH (Program Keluarga Harapan) di Desa Bandungrejo, hanya melakukan kegiatan rutin yang sifatnya sangat normatif seperti kegiatan pengajian, tahlil dan olahraga. Bahkan terkadang kegiatan itupun lebih banyak bersifat insidential seperti pengajian, mereka berkumpul untuk mendapatkan wawasan keagamaan seperti maulid dan sholawat. Padahal dibalik terselenggaranya kegiatan tersebut tersimpan potensi yang seharusnya dapat dikembangan dan bisa dilakukan oleh ibu rumah tangga di daerah tersebut. Kelompok ibu rumah tangga yang dibentuk oleh pemerintahan desa terlihat belum mampu dikembangkan dan dikelola dengan maksimal untuk memberdayakan potensi mereka. Dilihat dari jumlah ibu rumah tangga yang cukup banyak bisa menjadi kesempatan untuk mereka agar memberdayakan ke arah yang lebih positif, khususnya dalam peningkatan ekonomi keluarga. Minimnya penyuluhan dan motivasi bagi para ibu rumah tangga di desa Bandungrejo tidak menjadikan peluang untuk mengembangkan potensi yang sebenarnya, yang bisa dapat dioptimalkan untuk meningkatkan taraf hidup.

Dalam upaya untuk menumbuhkan motivasi dan kemampuan para ibu rumah tangga diperlukan penyuluhan dan pelatihan yang dapat menggerakkan para ibu rumah tangga untuk menemukan, mengembangkan dan meningkatkan potensi masing-masing (Karamina et al., 2020). Dengan adanya kesadaran dan motivasi tersebut, diharapkan para ibu rumah tangga dapat bertindak lebih jauh dan turut andil dalam menyelesaikan persoalan perekonomian keluarga. Dalam hal ini, potensi diri memiliki pengertian yang umumnya relatif dapat dipahami dengan mudah. Menurut Wiyono (2006) Pengertian potensi disini mengarah pada sebuah kemampuan dasar yang dimiliki manusia yang sangat mungkin untuk dikembangkan, sehingga pada intinya potensi sendiri berarti suatu kemampuan yang masih bisa dikembangkan menjadi lebih baik lagi. Desa Bandungrejo memiliki potensi yang layak untuk dikembangkan hingga menjadi sumber penghidupan bagi keluarga dan dapat mendorong perekonomian daerah.

\section{METODE}

Kegiatan berupa penyuluhan ini diselenggarakan bersamaan dengan kegiatan KSMTematik kelompok 93 Universitas Islam Malang di Desa Bandungrejo Dusun Sumberagung.Tahapan yang dilakukan yaitu (1) Observasi dan wawancara dengan ibu-ibu rumah tangga untuk memperoleh informasi tentang kondisi kelompok ibu rumah tangga yang ada di desa Bandungrejo; (2) Memberikan pelatihan yang bertujuan memberikan motivasi untuk mengenal dan menggali potensi diri yang dimiliki ibu rumah tangga sekaligus memanfaatkan komoditi lokal sebagai olahan yang memiliki nilai jual. 


\section{HASIL DAN PEMBAHASAN}

Keberadaan perempuan di bidang ekonomi adalah salah satu indikator meningkatnya kesejahteraan. Saat perempuan menjadi kaum terdidik, mempunyai hak-hak kepemilikan, dan bebas untuk bekerja di luar rumah serta mempunyai pendapatan mandiri, inilah tanda kesejahteraan rumah tangga meningkat (Supeni \& Sari, 2011). Sebagian besar ibu rumah tangga di Desa Bandungrejo tidak bekerja dan hanya mengandalkan penghasilan suami. Dalam upaya untuk menumbuhkan motivasi dan ke-mampuan atau skill para ibu rumah tangga di Dusun Sumberagung Desa Bandungrejo Kecamatan Bantur maka mahasiswa KSM TEMATIK kelompok 93 mempunyai rencana untuk mengadakan pelatihan.

Pelatihan yang akan diadakan berpedoman pada potensi yang dimiliki oleh desa Bandungrejo sendiri yakni buah pisang. Pisang merupakan salah satu plasma nutfah yang tersebar luas di wilayah Indonesia. Tanaman pisang (Musa sp) terbagi kedalam dua kelompok, yaitu pisang berbiji (liar) dan pisang yang dapat di konsumsi (Kurnianingsih et al., 2018). Indonesia merupakan asal dan pusat keanekaragaman pisang baik tipe liar dan kultivar (Daniells et al., 2001; Rifliyah, 2019). Menurut Kurnianingsih et al. (2018) kurang lebih 54 kultivar pisang ditemukan di Indonesia. Di desa Bandungrejo sendiri banyak tanaman pisang yang tumbuh hampir di setiap halaman rumah warga. Pelatihan yang akan dilaksanakan berfokus tentang bagaimana memanfaatkan buah pisang menjadi berbagai macam olahan dan juga bagaimana strategi pemasaran secara online yang bisa dilakukan secara mandiri oleh para ibu rumah tangga. Dengan adanya pelatihan ini, diharapkan para ibu dapat bertindak lebih jauh dan turut andil dalam menyelesaikan persoalan perekonomian keluarga. Karena sasaran kali ini adalah ibu rumah tangga yang tergabung dalam PKH (Program Keluarga Harapan) di Desa Bandungrejo.

Pelatihan yang akan dilaksanakan berjudul Pelatihan Strategi Pemasaran Melalui Media Online Pada Produk Usaha Rumahan Banana Chips. Pelatihan tersebut dilaksanakan pada tanggal 26 Agustus 2021. Pelaksanaan pelatihan di Desa Bandungrejo diawali dengan undangan yang diberikan kepada masing-masing ketua RT Dusun Sumberagung Desa Bandungrejo dimana setiap RT diminta mengirimkan 2 perwakilan.

Pemberian undangan tersebut menjadi penting karena memberikan informasi tentang tujuan dilakukannya program pelatihan tersebut sekaligus menggugah dan memotivasi para ibu rumah tangga untuk berpartisipasi dalam membantu peningkatan ekonomi keluarga. Dari 5 undangan RT yang telah disebar, hanya 8 orang perwakilan yang datang dari masing-masing RT. Para ibu rumah tangga yang hadir terlihat cukup antusias mendengarkan dan menyimak materi yang disampaikan.

Pelaksanaan pelatihan pengolahan dan pemasaran diawali dengan penyampaian materi tentang pengolahan banana chips dan strategi pemasaran melalui media sosial. Salah satu hal yang penting dalam menjalanlan sebuah usaha adalah konsep pemasaran baik peluang usaha baru maupuan usaha yang telah lama berjalan. Dalam konsep pemasaran, untuk dapat meningkatkan hasil penjualan tentunya pelaku usaha harus pandai dalam memasarkan produknya dari mulai promosi sampai menjual produknya. Kotler \& Keller (2007) mengungkapkan bahwa pemasaran merupakan kegiatan yang bertujuan untuk menciptakan pasar akan suatu produk. Strategi pemasaran atau bauran pemasaran (marketing mix) meliputi 4 hal, yaitu: Product, Price, Place, Promotion. Contoh strategi pemasaran konvensional yang diterapkan dari dulu hingga sekarang misalnya iklan, direct marketing, dan sales promotion.

Ketiga contoh tersebut bukan berarti tidak bermanfaat lagi di masa sekarang, namun perusahaan tentunya perlu mempertimbangkan media baru dan strategi baru agar pemasaran menjadi lebih efektif dan efisien. Adapun bagaimana proses pemasaran online di marketplace dalam hal ini Facebook dapat dijelaskan sebagai berikut (1) Login ke akun 
facebook kamu; (2) Setelah masuk klik Marketplace; (3) Klik “+ Jual Sesuatu”, lalu klik Item untuk Dijual; (4) Pilih kategori (contoh: barang), dan masukkan judul untuk daftar kamu, harga, dan lokasi kamu. Kamu juga dapat membuat deskripsi produk. Jika kamu ingin menandai item sebagai Gratis, Kamu dapat memasukkan 0 sebagai harga; (5) Klik + 10 Foto untuk mengunggah foto produk kamu dari gadget kamu.

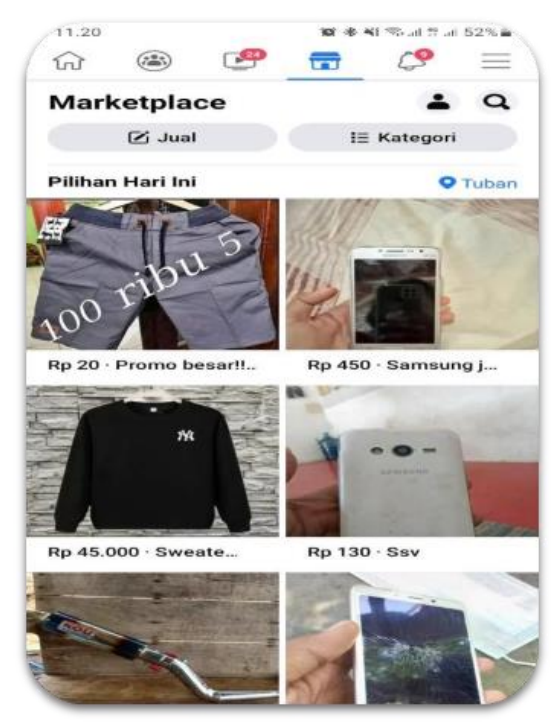

Gambar 1. Aplikasi Maerketplace

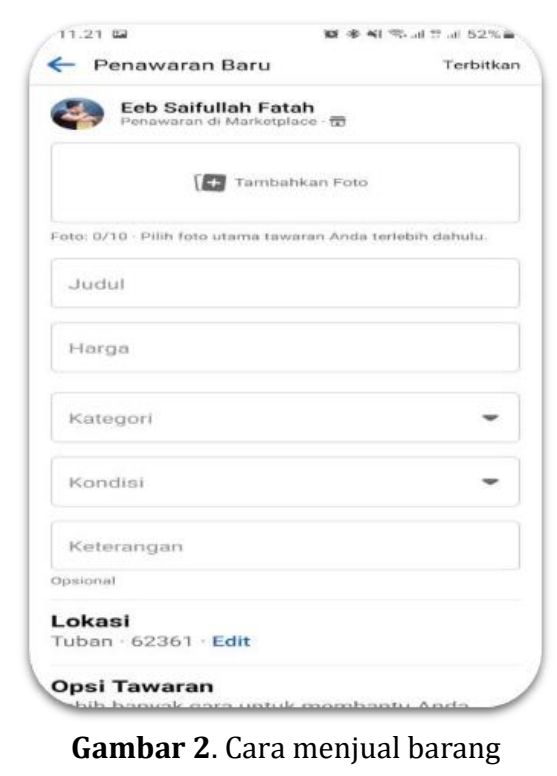

Di sela-sela penjelasan ini tampak para ibu-ibu baru menyadari bahwa sebenarnya pisang memiliki potensi untuk dikembangkan. Hal itu terlihat dari respon mereka pada saat sesi tanya-jawab yang berlangsung sangat cair dan akrab. Banyak di antara mereka yang mulai memiliki harapan terkait dengan bentuk pelatihan seperti apa yang mereka perlukan untuk mengembangkan dan memberdayakan potensi diri yang mereka miliki.

Kondisi ekonomi sebagian besar ibu-ibu kurang baik ditambah dengan pendidikan yang tidak memadai, kegiatan pelatihan ini setidaknya mampu membuka wawasan dan kesadaran mereka bahwa seorang ibu rumah tangga mempunyai potensi untuk mengembangkan diri dan bahkan berkreasi lebih baik lagi untuk membantu perekonomian keluarga. Banyak di antara mereka yang memang hanya menyandarkan kebutuhan rumah 
tangga kepada sang suami. Kesadaran seperti inilah yang kemudian diharapkan dapat membuka jalan mereka, terutama yang sangat minim informasi untuk mengembangkan potensi pisang. Melalui kegiatan pelatihan ini diharapkan bahwa para ibu rumah tangga bisa mengolah dan memasarkan hasil pisang dari kebun mereka sendiri untuk menambah pemasukan agar perekonomian mereka membaik.

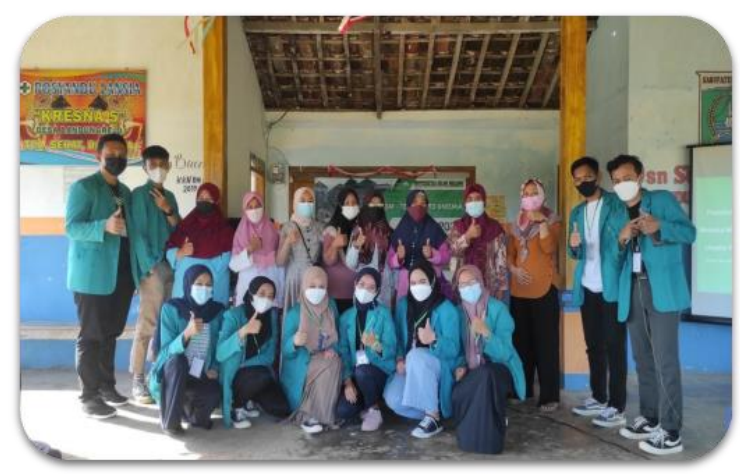

Gambar 3. Dokumentasi tim pengabdi beserta peserta

\section{KESIMPULAN}

Kegiatan pelatihan yang dilaksanakan oleh mahasiswa KSM TEMATIK UNISMA memberikan dampak yang positif kepada masyarakat, khususnya para ibu rumah tangga. Kegiatan di desa Bandungrejo tersebut membuka wawasan dan memberikan suasana dan energi baru bagi para ibu rumah tangga yang mengikuti kegiatan pelatihan. Mereka mulai menyadari bahwa tanaman pisang yang tumbuh dipekarangan rumah mereka bisa menjadi suatu produk yang menjanjikan dan mempunyai nilai tambah bila diolah terlebih dahulu. Mahasiswa KSM TEMATIK UNISMA berharap kegiatan pelatihan tersebut para ibu rumah tangga yang ada di desa Bandungrejo bisa menambah penghasilan keluarga dengan cara menciptakan produk dari pisang dan memasarkannya.

\section{DAFTAR RUJUKAN}

Daniells, J. W., Jenny, C., Karamura, D. A., \& Tomekpe, K. (2001). Musalogue: A catalogue of Musa germplasm. Diversity in the genus Musa. INIBAP.

Hamid, H. (2018). Manajemen Pemberdayaan Masyarakat (T. S. Razak (ed.); 1st ed.). De La Macca.

Hatneny, A. I., Mahardani, A. S., \& Saraswati, E. (2019). Pemberdayaan Masyarakat Pada UKM Depo Air Minum Tirta Barokah Dan Bakso Tuna Cintaku. Jurnal Inovasi Hasil Pengabdian Masyarakat (JIPEMAS), 2(1), 54-62. https://doi.org/10.33474/jipemas.v2i1.1604

Karamina, H., Supriyadi, S., Firman Yasin, D. D., Yusi Kamhar, M., \& Kusuma Astuti, F. (2020). Pemanfaatan dan Penanaman Tanaman Obat Keluarga (TOGA) Menuju Keluarga Sehat Pada Ibu Pemberdayaan Kesejahteraan Keluarga (PKK). Jurnal Inovasi Hasil $\begin{array}{lll}\text { Pengabdian } \quad \text { Masyarakat } & \text { (JIPEMAS), }\end{array}$ https://doi.org/10.33474/jipemas.v3i2.6416

Kotler, P., \& Keller, L. (2007). Manajemen Pemasaran, Jilid I, Edisi Kedua Belas. PT. Indeks. Kurnianingsih, R., Astuti, S. P., \& Ghazali, M. (2018). Karakterisasi Morfologi Tanaman Pisang di Daerah Lombok. Jurnal Biologi Tropis, 18(2), 235-240. https://doi.org/10.29303/jbt.v18i2.790

Rifliyah, K. (2019). Pengelompokan Genom Kulvitar Pisang Berdasarkan Karakter Morfologi dan Marka Molekuler ISSR (Inter-Simple Sequence Repeat). Universitas Islam Negeri Maulana Malik Ibrahim Malang. 
Sugiri, L. (2012). Peranan Pemerintah Daerah dalam Pemberdayaan Masyarakat. Publica, 2(1), 56-65. http://jurnal.ubl.ac.id/index.php/publica/article/view/404

Supeni, R. E., \& Sari, M. I. (2011). PENGEMBANGAN MANAJEMEN USAHA KECIL (Studi diskriptif pada Kegiatan Usaha Kecil Ibu-ibu Desa Wirolegi Kabupaten Jember, Dampingan Pusat Studi Wanita UM Jember). Prosiding Seminar Nasional \& Internasional, 101-111. https://jurnal.unimus.ac.id/index.php/psn12012010/article/view/411

Wiyono, S. (2006). Manajemen Potensi Diri (Revisi, Ce). Grasindo. 